\title{
OS DETERMINANTES DO COMÉRCIO INTRAINDÚSTRIA ENTRE O BRASIL, A UNIÃO EUROPEIA E A CHINA, NO PERÍODO DE 2006 A 2017: UMA APLICAÇÃO DO MODELO GRAVITACIONAL
}

Angel Maitê Bobato ${ }^{1}$ Daniel Arruda Coronel ${ }^{2}$ Paulo Ricardo Feistel ${ }^{3}$

Resumo: $O$ objetivo deste trabalho é identificar os determinantes do comércio intraindústria (CII) entre o Brasil, a União Europeia e a China, no período de 2006 a 2017. Para isso, utilizou-se o modelo gravitacional do comércio com dados em painel por Mínimos Quadrados Ordinários e por Poisson Pseudo-Maximun-Likelihood (PPML). Os dados foram coletados nos sítios do Comex Stat, Worl Bank e do CEPII. Em relação aos resultados alcançados, constatou-se que o comércio intraindústria brasileiro com a União Europeia e a China é baixo e apresentou queda ao longo do período analisado. Em relação aos determinantes, averiguou-se que o custo de comércio afeta negativamente este comércio, ou seja, quanto maiores são os custos de comercialização entre o Brasil e seus parceiros comerciais, menor tende a ser o Cll entre eles. Por outro lado, o tamanho econômico, a similaridade de renda e o grau de abertura do parceiro comercial afetam de forma positiva o Cll do Brasil com os parceiros analisados.

Palavras-chave: Comércio Intraindústria. Modelo Gravitacional. Brasil - União Europeia. Brasil - China.

\section{THE DETERMINANTS OF INTRA-INDUSTRY TRADE BETWEEN BRAZIL, THE EUROPEAN UNION AND CHINA, FROM 2006 TO 2017: AN APPLICATION OF THE GRAVITATIONAL MODEL}

Abstract: The objective of this paper is to identify the determinants of intra-industry trade (IIC) between Brazil, the European Union and China, from 2006 to 2017. For this, we used the gravitational model of trade with panel data by Least Squares. Ordinary and by Poisson Pseudo-Maximun-Likelihood (PPML). Data were collected from Comex Stat, Worl Bank and CEPII sites. Regarding the results achieved, it was found that Brazilian intra-industry trade with the European Union and China is low and showed a decrease over the analyzed period. Regarding the determinants, it was found that the cost of trade negatively affects this trade, that is, the higher the trading costs between Brazil and its trading partners, the lower the IIC tends to be between them. On the other hand, the economic size, income similarity and degree of openness of the trading partner positively affect Brazil's IIC with the analyzed partners.

Keywords: Intraindustry Trade. Gravitational model. Brazil- European Union. Brazil China

\section{LOS DETERMINANTES DEL COMERCIO INTRAINDUSTRIAL ENTRE BRASIL, UNIÓN EUROPEA Y CHINA, EN EL PERÍODO DE 2006 A 2017: UNA APLICACIÓN DEL MODELO GRAVITACIONAL}

\footnotetext{
1 Universidade de São Paulo - Escola Superior de Agricultura Luiz de Queiroz - USP/ESALQ, Departamento de Economia Aplicada, Piracicaba, Brasil, amaibobato@usp.br, https://orcid.org/00000001-6647-782X.

2 Universidade Federal de Santa Maria (UFSM), Departamento de Economia e Relações Internacionais, Santa Maria, Brasil, daniel.coronel@uol.com.br https://orcid.org/0000-0003-0264-6502.

${ }_{3}^{3}$ Universidade Federal de Santa Maria(UFSM), Departamento de Economia e Relações Internacionais, Santa Maria, Brasil, prfeistel@gmail.com https://orcid.org/0000-0002-6090-8278.
} 
Resumen: El objetivo de este trabajo es identificar los determinantes del comercio intraindustrial (CII) entre Brasil, Unión Europea y China, en el período de 2006 a 2017. Para esto, se utilizó el modelo gravitacional de comercio con datos de panel por Mínimos Cuadrados Ordinarios y por Poisson Pseudo-Maximun-Likelihood (PPML). Los datos se recopilaron en los sitios web de Comex Stat, Worl Bank y CEPII. Con respecto a los resultados alcanzados, se encontró que el comercio intraindustrial brasileño con Unión Europea y China es bajo y mostró una caída durante el período analizado. Con respecto a los determinantes, se encontró que el costo del comercio afecta negativamente a este comercio, es decir, cuanto más altos sean los costos de comercialización entre Brasil y sus socios comerciales, menor será el Cll entre ellos. Por otro lado, el tamaño económico, la similitud de los ingresos y el grado de apertura del socio comercial afectan positivamente el CII de Brasil con los socios analizados.

Palabras clave: Comercio Intraindustrial. Modelo gravitacional. Brasil - Unión Europea. Brasil- China.

\section{Introdução}

O comércio internacional, pós-Segunda Guerra Mundial, enfrentou grandes desafios para promover a liberação comercial. A criação do Acordo Geral sobre Aduanas e Comércio (GATT), por meio das rodadas de liberalização comercial e, posteriormente, a formulação da Organização Mundial do Comércio (OMC), contribuíram para a intensificação do processo de liberalização, principalmente por meio das reduções das barreiras tarifárias (MESQUITA, 2013; THORSTENSEN, 1998).

Krugman (1986) abordou que, após a Segunda Guerra Mundial, ocorreu também a mudança do padrão de comércio das economias, passando a predominar, na maioria das relações comerciais, o comércio intraindustrial, o qual se caracteriza como a troca de produtos da mesma indústria. Porém Boyrie e Kreinin (2012) afirmam que o surgimento de economias emergentes, como Brasil, China e Índia, proporcionou mudanças nos padrões de comércio, havendo o crescimento da relação interindústria. Isso teria acontecido pelo fato de que as relações Norte - Norte apresentam o comércio intraindústria, ao passo que as relações Norte-Sul possuem predominância do comércio interindustrial. De acordo com Greenaway e Milner (1989), essa discussão em relação a qual tipo de troca comercial existe entre os países desenvolvidos (Norte) e os países em desenvolvimento (Sul) é recorrente desde as análises de Leontief (1953), sendo que esses padrões estão relacionados a semelhanças de dotação de fatores, nível de desenvolvimento, entre outras questões. 
Entretanto, Yeats (1997) destaca que, apesar de haver, na teoria econômica, o consenso de que os países em desenvolvimento não apresentam vantagens comparativas em produtos industriais que demandam maiores níveis de capital, o padrão comercial desses países pode mudar através de políticas e preferências comerciais, e, dentre as principais medidas, estaria a redução de barreiras tarifárias e a criação de arranjos comerciais, entre outras medidas. Essas ações reduziriam a diferença de renda entre os países, possibilitando o fomento do comércio intraindústria entre os países Norte - Sul.

No que tange ao Brasil, este caracteriza-se como uma economia em desenvolvimento, dessa forma, suas relações comerciais são Norte-Sul e Sul- Sul. Convém ressaltar que o país, em 2017, foi o $26^{\circ}$ maior exportador do mundo, apresentando uma participação de 1,23\% no comércio mundial. Em 2017, o país exportou US $\$ 217,739$ bilhões, apresentando um aumento de 58,36\% comparado ao ano de 2006, em que exportou aproximadamente US $\$ 137,5$ bilhões. Já em relação às importações, em 2006, o volume foi de US\$95,9 bilhões e, em 2017, foi de aproximadamente US $\$ 157$ bilhões, ou seja, um aumento de cerca de $64 \%$ no período analisado (WTO-WORLD TRADE ORGANIZATION, 2007; 2018). Em 2017, os produtos que o país mais exportou foram soja (12\%), minério de ferro $(9,2 \%)$, petróleo bruto $(7,9 \%)$, açúcar bruto $(5,2 \%)$ e carros $(3,1 \%)$, enquanto os que mais importou foram petróleo refinado (8,1\%), peças de veículos (3,6\%), remédios embalados $(2,2 \%)$ e circuitos integrados $(2,2 \%)$ (OCE - OBSERVATÓRIO DE COMPLEXIDADE ECONÔMICA, 2019).

Tratando-se dos parceiros comerciais do Brasil, em relação aos blocos econômicos, a União Europeia é o principal parceiro, sendo que, em 2017, teve uma participação de $16,03 \%$ nas exportações e $21,28 \%$ nas importações brasileiras. 0 principal produto que o país comercializa com a União Europeia é o complexo da soja (13,3 \% das exportações para UE, em 2017), e o que mais o país importa são produtos manufaturados (representa 98,23 \% das importações brasileiras da EU em 2017).

Já referente aos países parceiros comerciais do Brasil, desde 2009, a China é o principal parceiro. O país exportou, em 2017, aproximadamente 48,3 bilhões de dólares para a China, sendo que ela teve uma participação nas exportações 
brasileiras de $21,8 \%$ e de $18,1 \%$ nas importações. Os outros maiores parceiros comerciais do Brasil, em 2017, foram Estados Unidos (US\$25,1 bi), Argentina (US $\$ 17,8$ bi), Holanda (US $\$ 7,57$ bi) e Alemanha (US $\$ 6,18$ bi). Em 2017, o que o Brasil mais exportou para a China foram soja em grão $(42,8 \%$ do total da pauta de exportação, ,aproximadamente US $\$ 20,3$ bi), minério de ferro ( $21,9 \%$ do total da pauta, US $\$ 10,9$ bi); óleo bruto de petróleo (15,5\%, equivalente a US $\$ 7,3$ bi), pasta química de madeira (5,4\% ou US\$215 milhões). Já em relação às importações brasileiras, também é a China (US\$27 b) o principal parceiro, em segundo lugar os Estados Unidos (US\$20,4 bi), depois Argentina (US\$9,3 bi), Alemanha (US\$ 9,3 bi) e Coreia (US $\$ 5,39$ bi). O que o Brasil mais compra da China são máquinas, aparelhos e instrumentos elétricos ou eletrônicos (32,4\% do total da pauta de importação, US\$ 8,9 bi); máquinas, aparelhos e instrumentos mecânicos (15,4\% ou US\$ 4,2 bi). (OCE, 2019; MDIC, 2018; MRE/DPR/DIC - DIVISÃO DE INTELIGÊNCIA COMERCIAL, 2018).

Apesar da importância tanto da União Europeia como da China para o comércio internacional brasileiro, há poucos estudos analisando o comércio intraindústria entre - Brasil e estes parceiros comerciais. Em relação à União Europeia, destaca-se a pesquisa de Baltar (2008), que analisa o comércio do Brasil com diversos blocos, entre eles a UE. Já em relação à China, pode-se citar o trabalho de Sarquis (2011) e Amann, Stona, Gewehr (2016). A principal conclusão obtida por estes autores é que o comércio entre o Brasil- China e Brasil- União Europeia é interindustrial. Entretanto, ressalta-se que, nessas pesquisas citadas, não houve a realização empírica da identificação de fatores determinantes do comércio intraindústria entre o Brasil e esses parceiros comerciais.

Pesquisas que analisem o comércio intraindústria são importantes, pois esse tipo de relação comercial contribui para o desenvolvimento dos países. De acordo com Baltar (2008, p.131), "as relações interindustriais favorecem a agregação de valor e permite que uma intensificação do comércio tenha um forte impacto sobre o crescimento das economias". Além disso, Hidalgo (1993) e Vasconcelos (2003) defendem que analisar de que forma ocorre o comércio internacional entre os países permite a elaboração da melhor estratégia de política comercial entre eles. 
Neste contexto, surge o seguinte questionamento: quais são os fatores que podem contribuir para uma relação intraindústria entre Brasil - União Europeia e Brasil - China? Assim, o objetivo deste trabalho é analisar os determinantes do comércio intraindústria entre o Brasil e os países da União Europeia e da China, no período de 2006 a 2017. Para isso, inicialmente é feito o estudo do comércio intraindústria agregado e por setores dos produtos comercializados entre o Brasil e a União Europeia e a China.

Como procedimentos metodológicos, utiliza-se o índice de Grubel e Lloyd para mensurar o comércio intraindústria entre o Brasil, a União Europeia e a China. Mas, para verificar os determinantes do comércio intraindústria brasileiro, foi estimado um modelo gravitacional do comércio através do método de dados em painel. Os dados de exportações e importações utilizados foram coletados no Comex Stat (2018), desagregados em quatro dígitos. Foram utilizados também dados retirados do Centre D'Estudes Prospectives et D'Informations Internationales (CEPII) e do World Bank.

Por fim, vale ressaltar que esta pesquisa busca contribuir para o fomento do comércio intraindústria entre os países analisados, pois, de acordo com Hidalgo (1993), o Cll proporciona economias de escala, o que leva a reduções nos custos unitários devido à elevação da produção. Dessa forma, permite uma gama maior de produtos e proporciona o poder de escolha pelo lado do consumidor. Além disso, como será inserida mais uma variável que capta os custos de comércio, pretende-se evidenciar a importância da formulação de políticas de facilitação do comércio. E, por último, pretende-se contribuir para o debate acadêmico sobre o tema.

Além desta introdução, o presente trabalho é composto por outras cinco seções. A segunda seção refere-se ao referencial teórico sobre o comércio intraindústria; a terceira aborda algumas análises empíricas desse tipo de comércio entre o Brasil e seus parceiros comerciais. A natureza dos dados, o índice utilizado na pesquisa e a descrição do modelo empírico, bem como as variáveis que serão utilizadas para a análise dos determinantes do comércio intraindústria compõem a quarta seção. Os principais resultados obtidos através da análise serão reportados na quinta seção. E, por fim, na sexta seção, são expostas algumas considerações finais. 


\section{Comércio Intraindústria e Comércio Interindústria: Fundamentação Teórica}

A discussão sobre em que cada economia deve especializar-se, ou seja, produzir e comercializar com seus parceiros comerciais vem desde Adam Smith, com as vantagens absolutas, e David Ricardo, com as vantagens comparativas. Posteriormente a estas teorias, outros modelos foram desenvolvidos com o intuito de identificar os padrões de comércio dos países.

Dentre esses modelos, pode-se citar o de Heckscher-Ohlin $(\mathrm{H}-\mathrm{O})$ da teoria neoclássica do comércio internacional. Este modelo afirma que os países possuem distintas dotações de fatores, e, dessa forma, países que são abundantes em capital devem especializar-se na produção e exportar bens capital - intensivos, enquanto que os países que possuem uma dotação maior de trabalho devem produzir e exportar bens que são trabalho-abundantes. Dessa maneira, o comércio do modelo $\mathrm{H}-\mathrm{O}$ é do tipo interindústria, ou seja, as trocas comerciais entre os parceiros comerciais são de produtos de indústrias distintas (SILVA; BITTENCOURT, 2017).

Entretanto, Leontief (1953), ao aplicar a teoria do modelo H-O para os Estados Unidos, não obteve os resultados de acordo com ela. Esse fato ocasionou outras análises empíricas utilizando o modelo $\mathrm{H}-\mathrm{O}$ e intensificou a discussão sobre a presença do padrão de comércio do tipo intraindústria entre os países. O comércio intraindústria (CII) é caracterizado quando "há simultânea importação e exportação de produtos de mesma origem industrial, pertencentes a uma mesma etapa do processo produtivo" (SILVA, BITTENCOURT, 2017, p.3).

Amann, Stona e Gewehr (2012) destacaram que o trabalho "The approach to bilateralism: a change in the structure of World trade" de Hildgert (1935) foi uma das primeiras pesquisas a evidenciar a existência de comércio intraindústria entre os países. Porém, há consenso na literatura de que a pesquisa feita por Balassa (1966) para a Comunidade Econômica Europeia (CEE) foi o trabalho percursor do comércio intraindustrial, visto que este autor observou que a grande maioria dos bens comercializados pelos países da CEE eram do tipo intraindústria e que esse comércio era maior entre os países que possuíam dotações de fatores semelhantes (CARMO, 2014). 
Grubel e Lloyd (1975) formularam um índice que capta a intensidade do comércio intraindústria entre dois países, denominado como Índice de Grubel e Lloyd, sendo esta metodologia a mais aplicada para a análise de comércio intraindustrial. Este índice varia de zero a um, e, quando assume o valor mínimo (zero), o comércio caracteriza-se como interindustrial, contudo, quando assume valor o comércio entre dois países é completamente intraindústria. Já Linder (1961) destaca os determinantes do comércio intraindústria, e, para o autor, quanto mais semelhantes são os atributos dos países em relação à renda e ao padrão de consumo, maior tende a ser o intercâmbio de produtos da mesma indústria, ou seja, produtos que possuem características semelhantes. Já os autores Lancaster (1980) e Krugman (1979), através da formulação de modelos teóricos, tentaram definir características para o comércio intraindústria. Dessa maneira, verificaram que esse tipo de comércio ocorre em mercados que apresentam competição monopolística, com presença, na maioria dos casos, de economias de escala e com diferenciação de produto, além disso, ressaltam que diferenças nos gostos e preferências dos consumidores são fatores que afetam o comércio intraindústria (GRANÇO, 2011).

Outra importante contribuição foi a de Helpman e Krugman (1985), que formularam um modelo em que analisaram tanto o comércio interindústria como o comércio intraindústria. Os autores verificaram que as vantagens comparativas dos países são determinantes do comércio interindústria, e as economias de escala explicam o padrão de comércio internacional intraindústria (CARMO, 2014; SILVA; BITTENCOURT, 2017).

Entretanto, essa conclusão de Helpman e Krugman (1985) sofreu objeções de outros autores da área, pois, de acordo com Falvey e Kierkowski (1987), as vantagens comparativas eram importantes para explicar o comércio do tipo intraindústria. 0 modelo de Falvey e Kierkowski (1987), conforme Silva e Bittencourt (2017, p.4), defende que o "país abundante em capital exportará os bens intensivos em trabalho qualificado, pois deverá possuir mão de obra mais qualificada, ao passo que o país escasso em capital, com mão de obra menos qualificada, exportará os bens intensivos em trabalho não qualificado". Entretanto, Greenaway e Tharakan (1986) discutem que 
a diferenciação de produtos e a renda per capita semelhantes possibilitam um padrão de comércio intenso e do tipo intraindústria.

Para Loertscher e Wolter (1980), as diferenças dos estágios de desenvolvimentos entre os países é um fator determinante do comércio intraindústria. Conforme estes autores, países desenvolvidos que comercializam com outros países desenvolvidos tendem a ter um padrão de comércio intraindústria mais intenso, assim como na comercialização entre dois países em desenvolvimento. Logo, países que apresentam estágios distintos de desenvolvimento tendem a ter o comércio entre eles do tipo interindustrial. Além disso, destacam que maiores mercados internos e menores custos de comércio, como barreiras tarifárias, determinam um comércio intraindústria mais intenso entre os países. A Organização de Cooperação e de Desenvolvimento Econômico (OCDE, 2002) destaca que o grau de abertura dos países afeta positivamente o comércio intraindústria, pois países com maiores graus de abertura econômica apresentam maiores possibilidades de apresentarem padrões de comércio intraindustrial.

Entretanto, para Moreira e De Paula (2010), o que determina o comércio intraindústria são as inovações tecnológicas dadas as diferenças existentes nas tecnologias entre os países. Para os autores, esse fator determina o modo da inserção internacional das economias e possibilita a adaptação de produtos para os variados mercados e, com isso, a elevação de renda nos países. Logo, os autores corroboram com a ideia de que o comércio intraindústria está ligado às economias de escala e às diferenças de dotação de fatores. Ainda Paula e Miranda (2017) ressaltam que, quando os países que comercializam possuem semelhanças em relação à razão dos fatores de produção, o padrão de comércio intraindustrial tende a prevalecer na maioria das análises, e isso ocorre devido a semelhanças de tecnologia e de estágios de desenvolvimento de cada nação.

\section{Evidências Empíricas do Comércio Intraindústria Entre o Brasil e Seus Parceiros Comerciais}

Desde a década de 1980, a análise empírica do comércio intraindústria entre o Brasil e seus parceiros comerciais, sejam eles blocos econômicos ou países, tem sido 
a proposta de variados tipos de estudos usando diferentes metodologias. Dessa forma, a seguir, serão abordados alguns desses trabalhos que dispenderam esforços para a análise do comércio intraindúsria brasileiro. Primeiro, são apresentados os trabalhos que avaliaram o comércio intraindústria utilizando algum índice de comércio internacional e, posteriormente, trata-se das pesquisas que propuseram identificar os determinantes do comércio intraindústria entre o Brasil e determinado parceiro comercial.

O estudo de Oliveira (1986) foi pioneiro nas análises sobre comércio intraindústria no Brasil, visto que destacou que o comércio intraindústria pressupõe diferenciação de produtos, economias de escala e competição monopolística, sendo então uma generalização da teoria do modelo de Heckscher-Ohlin- Samuelson, que afirma ser o padrão de comércio o tipo interindústria (CARMO; BITTENCOURT, 2013).

Ainda nesta perspectiva, Oliveira (1986) analisou o comércio intraindústria dos países integrantes da Associação Latino América de Integração (ALADI) bem como 0 Cll do Brasil com seus principais parceiros industriais, no período de 1969 a 1982. Como metodologia, a autora utilizou o Índice de Grubel-Lloyd, o coeficiente de Aquino e as elasticidades de comércio intraindústria (através de MQO) em diferentes categorias manufatureiras e para diferentes países. A autora utilizou dados da balança comercial brasileira de 24 categorias de produtos manufaturados que representavam $68,2 \%$ do comércio total manufatureiro no período analisado. $O$ resultado desse estudo mostrou que os países da Aladi (Associação Latino-Americana de Integração) apresentaram comércio intraindústria menor quando comparado ao dos países industriais; para o Brasil, constatou ainda que o comércio intraindustrial apresentou uma trajetória crescente e significativa nos quatorze anos analisados.

A fim de relacionar o tipo de comércio brasileiro com características de estrutura industrial do Brasil, Baltar (2008) utilizou o indicador de comércio desenvolvido por Fontagné e Freudenberg (1997) e a classificação de Pavitt, em dois períodos do tempo, de 1996 a 1998, ou seja, antes da desvalorização do real, e de 2003 a 2005, que, conforme a autora, foi um período de forte crescimento do comércio internacional. Utilizando dados desagregados em seis dígitos para os blocos econômicos Mercosul, Nafta, União Europeia, Ásia, Aladi, e o resto do mundo, Baltar (2008) concluiu que o 
comércio brasileiro, em 1996-1998 e 2003-2005, era do tipo unilateral, o que significa que o país exportava produtos sofisticados para países que se encontravam em desenvolvimento e importava grande volume de produtos de valor agregado de países desenvolvidos, e ainda exportava para as grandes potências seus produtos primários, que são característicos por possuírem um baixo valor agregado. Baltar (2008) ressaltou, em sua pesquisa, que o Brasil precisa investir em desenvolvimento industrial para que o comércio seja capaz de contribuir com o dinamismo da economia brasileira, e para que assim o crescimento do país seja impulsionado.

Moreira e De Paula (2010) mensuram o comércio intraindústria entre o Brasil e os Estados Unidos, no período de 1997 a 2008, utilizando o índice de Grubel e Lloyd. Os autores discutem que a necessidade de uma indústria com um maior grau de desenvolvimento e globalizada ocasionou mudanças nas relações comerciais entre $o$ Brasil e os Estados Unidos. Sendo assim, obtiveram que o comércio entre esses dois países é caracterizado pelo intercâmbio de produtos industriais intermediários. Além disso, o comércio entre eles tem a forma de relação Norte- Sul, e isso ocorre porque os Estados Unidos são uma potência mundial desenvolvida, as relações relativas de capital - trabalho são muito diferentes entre os países, ou seja, o comércio entre esses países é predominantemente intraindustrial, com exceções das trocas dos setores com valor agregado. Segundo os autores, esses setores tendem a apresentar altos níveis de comércio intraindústria, independentemente de qual relação comercial esteja sendo analisada.

Silva, Silva, Zilli (2010) analisaram a evolução do comércio intraindústria e como este tipo de comércio contribui para o crescimento do volume comercializado entre o Brasil e a Argentina, no período de 1990 a 2007. Como metodologia, utilizaram o método de Menon e Dixon (1997). Os autores verificaram que o Mercosul contribuiu para que as trocas comerciais entre o Brasil e Argentina mudassem de interindústria para intraindústria, dessa maneira, a formação de blocos econômicos pode ser considerada um fator importante para o crescimento do comércio intraindústria entre os países. Constataram, ainda, que o comércio intraindústria contribui menos que o comércio interindústria no crescimento dos fluxos comerciais do Brasil e Argentina. 
Amann, Stona, Gewehr (2016) estudaram o comércio intraindústria entre o Brasil e um grupo de países desenvolvidos (Estados Unidos e Alemanha) e um grupo de países em desenvolvimento (Argentina, México e China), no período de 1997 e 2013. Vale destacar que os autores analisaram somente setores de cunho industrial. Por meio do índice de GL, não constataram a existência de um padrão intraindústria entre o Brasil e os países desenvolvidos e em desenvolvimento. A identificação de padrão intraindústria só foi encontrada em alguns setores das relações bilaterais entre Brasil e os países desenvolvidos e em desenvolvimento, que é o caso da indústria de automóveis entre Brasil e Argentina, a indústria de veículos automóveis entre Brasil e Alemanha, no período de 2005 a 2010, a indústria de máquinas entre Brasil e México e, por último, a indústria de aeronaves e suas partes entre o Brasil e os Estados Unidos, no período de 2007 a 2013. Dessa forma, o comércio intraindústria pode ser utilizado como mecanismo para o progresso técnico nos países.

Até aqui, foram abordadas as pesquisas que discutiram apenas a magnitude do comércio. Entretanto, além de verificar a existência do comércio intraindústria, mais relevante ainda é identificar os fatores que determinam esse tipo de padrão de comércio, pois, dessa maneira, políticas específicas podem ser realizadas, contribuindo para o crescimento do comércio intraindústria. Assim sendo, a seguir serão apresentadas pesquisas que dispenderam esforços para analisar os determinantes do comércio intraindústria do Brasil.

Hidalgo (1993) analisou o comércio intraindústria em nível de país, indústria e de comércio bilateral entre o Brasil e o resto do mundo, no período de 1978 a 1987. Através do Índice de Grubel-Lloyd, o autor verificou que 40\% do comércio total de manufaturados do Brasil era do tipo intraindústria. Ainda nesta perspectiva, o autor utilizou o Índice de Grubel-Lloyd como variável dependente em uma análise econométrica. O autor concluiu que, ao nível de indústria, o que determina positivamente o comércio intraindústria são o grau de diferenciação dos produtos e a intensidade comercial com os países que possuem renda per capita parecidas, já as indústrias brasileiras protegidas com barreiras tarifárias e com salários médios maiores tendem a ter um comércio intraindústria menor. 
Carmo e Bittencourt (2013) mensuraram o volume e o índice de comércio intraindústria entre o Brasil e os países que compõem a Organização de Cooperação e de Desenvolvimento Econômico (OCDE), no período de 2000 a 2009, utilizando dados desagregados a seis dígitos. Usaram a metodologia de Greenaway, Hine e Milner (1994) e o Índice de Grubel-Lloyd para analisar o comércio intraindústria. Os autores concluíram que o comércio intraindústria brasileiro com os países da OCDE era verticalmente inferior, ou seja, os produtos que o Brasil exporta apresentam uma qualidade inferior à dos produtos que o país importa de seus parceiros da OCDE, assim como Baltar (2008) obteve. Então, devido a isso, os autores utilizaram um modelo gravitacional para verificar os determinantes do comércio intraindústria vertical inferior entre o Brasil e os países parceiros da OCDE. Como resultado, constaram que - Estados Unidos e o México são os países que apresentaram maior volume e também maior índice de comércio intraindustrial com o Brasil. Além disso, o setor de máquinas/elétrico apresentou a maior magnitude de comércio intraindustrial no período analisado. Em relação à análise do modelo gravitacional, concluíram que o tamanho do mercado e a dotação de fatores têm impacto positivo sobre o volume intraindustrial vertical bilateral. E a distância geográfica afetou negativamente, corroborando com as hipóteses dos determinantes do comércio intraindústria.

Paula e Miranda (2017) analisaram o padrão e o desempenho do comércio entre o Brasil e os países do bloco econômico BRICS: Rússia, Índia, China e África do Sul, no período de 1997 a 2013. Como resultado, evidenciaram que o tamanho econômico e as variáveis culturais e as geográficas dos países afetam positivamente os fluxos comerciais do comércio entre o Brasil e os países que compõem o BRICS. A diferença de dotação relativa entre os fatores afetou negativamente o comércio intraindústria, dessa forma, os autores obtiveram que dotações similares de renda tendem a contribuir para que o comércio intraindustrial ganhe importância no comércio total.

Castellano, Oliveira e Bittencourt (2019) buscaram avaliar e mensurar a qualidade do comércio intraindústria entre o Brasil e os trinta e cinco países que compõem a OCDE, no período de 2001 a 2016. Utilizaram como método o índice de GL e o método de Fontagné e Freudenberg e, posteriormente, estimaram os 
determinantes desse comércio por meio do modelo gravitacional do comércio com efeitos fixos. Como resultado, verificaram que há diferenciação vertical entre os produtos exportados e os importados pelo Brasil para cada membro da OCDE. Em relação aos determinantes do comércio intraindústria vertical entre o Brasil e os países da OCDE, constataram efeito positivo da diferença entre a dotação de recursos e o tamanho da economia, e efeito negativo da distância geográfica, sendo esta última variável proxy para os custos de transportes.

\section{Metodologia}

Para a mensuração do Cll, utilizou-se índices que permitem a verificação do comportamento do comércio entre o país $j$ e o país $i$. Na literatura, a maioria das pesquisas, como foi possível observar na seção anterior, utiliza como aporte metodológico para captar o comércio intraindustrial o índice desenvolvido por Grubel e Lloyd (1975). Ressalta-se que existem outras formas de análises, mas, na literatura, há o consenso de que o Índice de Grubel e Lloyd é o mais eficiente para a mensuração do comércio intraindústria.

Desta forma, nesta pesquisa, utilizou-se o Índice de Grubel- Lloyd para verificar o comportamento do comércio entre o Brasil e os países da União Europeia e a China. O Índice Grubel- Lloyd ${ }^{4}$ (IGL) pode ser descrito da seguinte forma:

$$
I G L_{k i j t}=C I I_{k i j t}=1-\frac{\sum_{k=1}^{n}\left|X_{k i j t}-M_{k i j t}\right|}{\sum_{k=1}^{n}\left(X_{k i j t}+M_{k i j t}\right)}
$$

k: produto ou setor;

i: Brasil;

j: Países que compõem a União Europeia e a China;

$t:\{2006 \ldots 2017\}$.

Em que:

$X_{k i j t}$ : valor monetário das exportações do produto/setor $k$ do país $i$ para o país $j$ no ano $t$;

$M_{k i j t}$ : valor monetário das importações do produto/setor $k$ do país $i$ para o país $j$ no ano $t$.

Conforme Grubel e Lloyd (1975), este índice varia no intervalo de $(0,1)$. Resultado próximo de 0 é indicativo de comércio do tipo interindustrial, e, quanto mais próximo da unidade (1), maior é a representatividade do comércio intraindustrial (CII),

${ }^{4} \mathrm{O}$ índice está baseado em GRUBEL, H. G.; LLOYD, P. J. Intra-Industry Trade: The Theory and Measurement of International Trade in Differentiated Products. London, MacMillan, 1975. 
ou seja, o país $i$ exporta/importa com os países $j$ produtos $k$ da mesma indústria. Para os setores, será utilizada a classificação usada por Thorstensen et. al. (1994), que os agrupa em: I) alimentos e bebidas; II) minerais; III) produtos químicos; IV) plásticos e borracha; V) calçados e couros; VI) madeira e mobiliário; VII) papel e celulose; VIII) têxtil; IX) minerais não metálicos; $\mathrm{X}$ ) metais comuns; $\mathrm{XI}$ ) máquinas e equipamentos; XII) materiais de transporte; XIII) ótica e instrumentos; XIV) outros. Destaca-se que esta classificação foi utilizada por outros autores como Feistel e Hidalgo (2011) e escolhida pela compatibilidade com a base de dados utilizada nesta pesquisa.

\section{Modelo Gravitacional Do Comércio Por Dados Em Painel}

Para a análise empírica dos determinantes do comércio intraindustrial entre o Brasil e os países da União Europeia e a China, foram estimados modelos econométricos usando o modelo gravitacional na forma de painel de dados.

A utilização do modelo gravitacional iniciou-se na década de 1960, com as contribuições de Tinbergen (1962) e Linnermann (1966), entretanto, apesar de todo o aporte que esse modelo deu para a literatura sobre economia internacional, ele recebeu muitas críticas nessa época, sendo a principal a falta de embasamento teórico que interligasse o modelo com as teorias do comércio internacional (SOUZA; BURNQUIST, 2011; MISSAGGIA; FEISTEL, 2015). Devido a isso, uma série de trabalhos foram elaborados utilizando esse modelo com intuito de aprimorar esta forma de análise.

Autores como Anderson (1979), Bergstrand (1989), Anderson e Van Wincoop (2003, 2004), Souza e Burnquist (2011) contribuíram para melhorias no modelo gravitacional utilizando abordagens microeconômicas. Paula e Miranda (2017) destacam que o modelo gravitacional ampliado tem sido muito utilizado no comércio intraindústria, o qual se caracteriza pela inserção de outras variáveis além das tradicionais do modelo gravitacional, que são o produto interno, o produto dos países e a distância geográfica.

Com base no modelo de Paula e Miranda (2017), utilizou-se o modelo gravitacional aumentado para analisar os determinantes do comércio intraindústria 
entre o Brasil e os países da União Europeia e a China, no período de 2006 a 2017. Formula-se o seguinte modelo empírico a ser estimado:

$$
\begin{aligned}
\operatorname{lnCII}_{i j t}= & \alpha_{0}+\alpha_{t}+\beta_{1} \ln \left(D_{i s t_{i j}}\right)++\beta_{2} \ln \left(G a b_{j t}\right)+\beta_{3} \ln \left(D I F_{i j t}\right)+\beta_{4} \ln \left(P I B_{T_{i j t}}\right)+ \\
& \beta_{5} \ln \left(T C_{i j t}\right)+\beta_{6} \ln \left(S I M_{i j t}\right)+\theta_{i j}+u_{i j t}
\end{aligned}
$$

Onde: $C_{i j t}$ é o índice de comércio intraindustrial entre o país $i$ (Brasil) e o país $j$, no ano $t ; \alpha_{0}$ é o intercepto, que é comum para todos os anos e para todas as relações bilaterais de comércio; $\alpha_{t}$ é o intercepto que varia com o tempo, mas é comum para todas as relações bilaterais de comércio; Dist $_{i j}$ é a distância geográfica entre o Brasil e o seu parceiro comercial $j$; Gab $b_{j t}$ é o grau de abertura do parceiro $j$; DIF $F_{i j t}$ representa a diferença na dotação de fatores do Brasil e do país $j$, no ano $t$; PIB_T $T_{i j t}$ representa a soma total do Produto Interno Bruto (PIB) do Brasil com o PIB do país $j$, no ano $t ; T C_{i j t}$ é uma proxy para custos de comércio entre o Brasil e os seus parceiros comerciais; $S I M_{i j t}$ é um índice de similaridade que mostra o tamanho relativo de cada país em relação aos PIBs (Arelanes, 2009); $\theta_{i j}$ é a heterogeneidade não observada presente nas relações bilaterais de comércio, que é invariante no tempo; $u_{i j t}$ corresponde ao termo de erro.

Como já destacado, o $C_{i j}$ é o índice de comércio intraindustrial obtido pelo índice de Glubel e Lloyd representado pela Equação 1. Grau de abertura dos países é obtido pela relação da corrente de comércio (exportação + importação) do país em relação ao seu produto interno bruto (PIB), assim como fizeram Carmo e Bittencout (2013). Porém a variável de dotação de fatores é obtida pela diferença absoluta no PIB per capita do Brasil com o parceiro $j$, a renda per capita pode ser utilizada como proxy de dotação de fatores por possuir uma relação positiva com a razão capital/trabalho (HELPMAN, 1987). A variável similaridade $\left(\operatorname{Sim}_{i j t}\right)$ é obtida através da seguinte Equação:

$$
\text { Ln Sim }_{i j t}=\ln \left[\left(P I B_{i t} / P I B_{i t}+P I B_{j t}\right)^{2}-\left(P I B_{j t} / P I B_{i t}+P I B_{j t}\right)^{2}\right]
$$


Em que: PIBit é o produto interno bruto do Brasil no ano $t$; $P I B_{j t}$ é o produto interno bruto do país $j$ no ano $t$. $O$ Quadro 1 contém uma descrição com acuidade de todas as variáveis e os sinais esperados.

Quadro 1 - Descrição, Fonte e sinal esperado das variáveis explicativas

\begin{tabular}{|c|c|c|l|}
\hline Variável & Fonte & $\begin{array}{c}\text { Sinal } \\
\text { Esperado }\end{array}$ & \multicolumn{1}{c|}{ Descrição } \\
\hline Dist $i j$ & CEPII & - & Distância geográfica em Km, proxy de custo de transporte \\
\hline Gab $_{j t}$ & World Bank & + & Grau de abertura da economia $j$ (países da EU e a China). \\
\hline$D I F_{i j t}$ & World Bank & - & $\begin{array}{l}\text { Representa a proxy para a diferença de dotações de fatores entre } \\
\text { os parceiros comerciais. } \\
\text { É o produto interno bruto total entre o país } i \text { e } j \text {, soma do PIB com } \\
\text { o PIB }\end{array}$ \\
\hline$P I B \_T_{i j t}$ & World Bank & + & $\begin{array}{l}\text { Proxy de custo de comércio, refere-se ao número em dias para } \\
\text { que um país se adapte para exportar, processos alfandegários, } \\
\text { obtenção de certificados }\end{array}$ \\
\hline$T C_{i j t}$ & $\begin{array}{c}\text { Doing } \\
\text { Business }\end{array}$ & - & $\begin{array}{l}\text { Proxy para similaridade e mostra o tamanho relativo de cada país } \\
\text { (Arelanes et. al, 2009). }\end{array}$ \\
\hline$S I M_{i j t}$ & World Bank & + &
\end{tabular}

Fonte: Elaboração própria

Ressalta-se que o número de observações são 348 (12 anos X 28 países da União Europeia + China), Dado isso, na próxima subseção serão apresentados os procedimentos utilizados para a estimação do modelo gravitacional.

\section{Métodos e Procedimentos de Estimação}

Para a presente pesquisa, tem-se um período de doze anos e vinte e oito países, que são as unidades de corte. Dessa forma, a maneira mais apropriada de estimação do modelo reportado na seção anterior são os painéis de dados. De acordo com Baltagi (2005), o painel de dados, também conhecido como dados em painel, caracteriza-se por analisar uma dimensão espacial e outra dimensão temporal. Dessa maneira, o comércio intraindústria entre o Brasil e cada um dos países da União Europeia e a China é analisado ao longo do tempo, que, neste caso, é reportado em anos.

Baltagi (2005) e Greene (2012) ressaltam que a utilização do método de estimação em dados em painel apresenta algumas vantagens frente a outras formas de estimação como cross-section. Por combinar várias unidades de corte ao longo de várias unidades de tempo, tem-se a primeira vantagem dos dados de painel, que é o 
aumento do tamanho da amostra, proporcionando, assim, mais graus de liberdade para a realização da pesquisa, maiores ganhos de informação, aumento de variabilidade e, com isso, a diminuição da colinearidade entre as variáveis, fazendo com que o modelo estimado apresente uma maior eficiência. Este tipo de estimação tem a vantagem de permitir a captação da heterogeneidade dos países e proporcionar a análise da dinâmica do tempo (GREENE, 2012).

A grande questão tratada na análise de painel de dados é em relação a como tratar a heterogeneidade entre os sujeitos para obter resultados consistentes e não viesados (WOOLDRIDGE, 2006). Dessa forma, há duas formas de estimação que considera a presença da heterogeneidade na pesquisa: efeitos fixos e efeitos aleatórios, sendo a principal questão se a heterogeneidade é estocástica ou não, ou seja, verificar se tal heterogeneidade possui correlação com os regressores do modelo (GREENE, 2012).

Os efeitos fixos são característicos por possibilitarem que a variável que não é observada e que é constante no modelo, como efeito de colonização e outros fatos histórico e geográficos, se correlacione com as outras variáveis explicativas. Souza e Burnquist (2009) destacam que, no comércio internacional, os efeitos fixos captam características próprias e particularidades comerciais de cada país. Existe uma discussão na literatura sobre qual efeito fixo deve-se utilizar na estimação do modelo gravitacional. Para Cheng e Wall (2004), os efeitos são dois, um para cada par de país e outro para cada ano $t$. Já Baldwin e Taglioni (2006) e Magee (2008) afirmam que podem ser inseridos três tipos de efeito fixo: um constante no tempo, que será igual para cada par de país que analisar; outro efeito fixo específico para o importador $i$ em cada ano $t$ e um terceiro efeito fixo específico para exportador para cada ano $t$. Vale destacar, que esses efeitos fixos têm o objetivo de controlar a resistência multilateral do comércio. Neste estudo, foram utilizados os efeitos fixo de tempo e efeito fixo país -ano. Entretanto, é necessário destacar que, como está sendo analisado o comércio intraindústria do Brasil, o país é invariante, dessa maneira, variará apenas o país $j$. Sendo assim, julga-se suficiente o efeito fixo de país-ano, que pode ser denominado efeito específico para $o$ importador $j$ em cada ano $t$, procedimento semelhante realizado por Martins (2018). 
Quando constatada a presença de heterogeneidade entre os indivíduos, mas sem correlação com os regressores, tem-se nesse modelo a presença de efeitos aleatórios. Para verificar qual efeito utilizar, alguns testes devem ser realizados entre os modelos. O multiplicador de Lagrange testa o efeito aleatório com o efeito pooled, onde a hipótese nula assume que o modelo é pooled e a hipótese alternativa considera que deve ser estimado o modelo de efeitos aleatórios (GREENE, 2012). Ou seja, se aceitar a hipótese nula, o correto é estimar pooled, caso contrário, se esta hipótese for rejeitada, prevalece o efeito aleatório. O Teste de Chow verifica a eficiência entre o modelo pooled e os efeitos fixos. A hipótese nula considera que o modelo é do tipo pooled, e a hipótese alternativa, que o modelo é de efeito fixo. Logo, rejeitando a hipótese nula, aceita-se o modelo por efeito fixo.

Ainda é necessário comparar o modelo de efeito fixo contra o modelo de efeito aleatório, e isso é realizado através do Teste de Mundlak nesta pesquisa, por ser mais robusto na presença de heterocedasticidade e correlação contemporânea. A hipótese nula aceita o modelo de efeito aleatório, e a hipótese alternativa considera correto o modelo de efeito fixo. Se rejeitar a hipótese nula, devem ser estimados os dados em painel por efeito fixo, mas ressalta-se que este efeito não aceita variáveis constantes no tempo, por exemplo idioma, fronteira e outros.

Conforme o efeito obtido através dos testes, é necessário ainda realizar testes de heterocedasticidade para verificar se a premissa de variância homocedástica é garantida nos modelos. Para isso, utilizam-se os testes de Wald. Para verificar se há problemas de autocorrelação e correlação contemporânea, são realizados os testes de Wooldridge e Pesaran.

Nesta pesquisa, para analisar qual é a melhor forma de estimação e também para ganho de robustez, foram estimados o modelo pooled (que consiste em apenas empilhar os dados, rejeitando as heterogeneidades dos sujeitos) e os modelos de efeitos fixos e efeitos aleatórios. Para decidir qual modelo é o "bechmark", são realizados os testes discutidos acima.

Ainda, utilizou-se outra forma de estimação mais robusta, que é o método Poisson Pseudo- Maximum- Likelihood (PPML), introduzido por Santos Silva e Tenreyro (2006). Conforme o autor, a principal contribuição desse estimador é a 
eficiência em estimar modelos que possuem muitos valores zeros ou valores faltantes, e que possuem robustez na presença de heterocedasticidade. De forma geral, a principal mudança ao estimar por PPML é que a variável dependente é estimada na forma em nível, ou seja, utilizando a metodologia do modelo gravitacional, a estimação ocorre na forma não linear, ou lin-log.

\section{Fonte dos Dados}

Para atingir os objetivos específicos neste trabalho, foram coletados os dados referentes às exportações e importações do Brasil para os países do bloco econômico União Europeia ${ }^{5}$ e para a China, no sítio da Comex Stat. Os dados coletados são os valores monetários (em dólares), conforme o Sistema Harmonizado com desagregação de quatro dígitos, para o período de 2006 a 2017. Este período foi escolhido por disponibilizar todas as variáveis necessárias ao estudo. Destaca-se que todos os dados coletados para as variáveis monetárias estão em dólares.

Silva e Bittencourt (2017) salientam que utilizar a desagregação de produtos por quatro dígitos evita que a mensuração do comércio intraindústria através do Índice de Grubel- Lloyd seja superestimada, além disso, segundo os autores, possibilita a identificação dos produtos dentro de cada indústria.

Os dados referentes ao Produto Interno Bruto (PIB) e a Renda per capita do Brasil e de seus parceiros comerciais foram coletados do Banco Mundial (World Development Indicators). As exportações e importações dos parceiros comerciais, utilizados para o cálculo da abertura comercial, também foram obtidos junto ao Banco Mundial (World Development Indicators).

Os dados de distância geográfica, proxy de custo de transporte, foram obtidos no site Centre D'Estudes Prospectives et D'Informations Internationales - CEPII. A distância geográfica utilizada foi a que é calculada em quilômetros $(\mathrm{Km})$ entre as principais cidades do país e não pelas distâncias das capitais.

Para a análise deste estudo, foi usado como custo de comércio a proxy Tempo em dias, a qual foi obtida no site "Doing Business", mantido pelo The World Bank Group (2018).

\footnotetext{
${ }^{5}$ A União Europeia é formada por 28 economias: Alemanha, Áustria, Bélgica, Bulgária, República Tcheca, Chipre, Croácia, Dinamarca, Eslováquia, Eslovênia, Espanha, Estônia, Finlândia, França, Grécia, Hungria, Irlanda, Itália, Letônia, Lituânia, Luxemburgo, Malta, Países Baixos, Polônia, Portugal, Reino Unido, Romênia e Suécia.
} 


\section{Análise e Discussão dos Resultados}

Inicialmente, foi analisado o comércio intraindústria entre o Brasil, a União Europeia e a China. Para isso, o índice desse tipo de comércio foi mensurado para a União Europeia como um todo, e, para uma análise mais aprofundada, foi calculado para o comércio bilateral entre o Brasil e os vinte e oito países que compõem este bloco econômico. Além do índice de Grubel e Lloyd (IGL) agregado, foi mensurado, tanto para a União Europeia como para a China, o IGL por setores, utilizando a Classificação de Thorstensen et. al. (1994, p. 50-51).

Percebe-se, através da Tabela 1, que o comércio intraindustrial como um todo entre o Brasil e o bloco econômico da União Europeia apresentou um IGL que variou de $16 \%$ a $24 \%$ no período analisado, apresentando um IGL médio anual igual a $20 \%$. Contudo, ao se comparar 2006 com 2017, nota-se que o comércio intraindustrial brasileiro com o bloco europeu diminuiu, sendo que o maior IGL obtido foi no ano de 2006, quando 24\% do comércio entre o Brasil e União Europeia era do tipo intraindústria, e o menor índice verificado no período foi no ano de 2016 , quando 16\% do comércio era intraindustrial. Baltar (2008) analisou o comércio intraindústria Brasil -UE nos períodos de 1996-1998 e 2003-2005, utilizando o índice de Fontagné e Freudenberg, constatou níveis ainda mais baixos de comércio intraindústria, 12,9\% e $9,2 \%$, respectivamente. Dessa forma, percebe-se que o comércio agregado com a União Europeia vem ocorrendo desde os anos 90, predominantemente interindustrial.

Analisando, agora, o comércio intraindústria entre o Brasil e os países que compõem a União Europeia, percebe-se que o IGL também diminuiu de 2006 para 2017 na maioria das relações bilaterais. O comércio brasileiro com Chipre, Itália e Bulgária, em 2006, foi completamente do tipo interindustrial, considerando que o IGL foi igual a zero nesse ano. Entretanto, ainda no ano de 2006, alguns países apresentaram comercialização intraindustrial mais intensa com o Brasil, ou seja, apresentaram maiores IGLs, esses países foram Alemanha $(0,24)$, Dinamarca $(0,23)$ e França $(0,19)$.

Em 2017, o único IGL igual a zero foi entre o Brasil e o Chipre, e novamente observa-se que os países que apresentaram os menores IGL em 2017 são os mesmos 
de 2006. Entretanto, a Itália e a Bulgária, que tinham IGL de 0\% em 2006, passaram a ter um comércio intraindústria com o Brasil de $1 \%$ em 2017. Dinamarca $(0,35)$, Alemanha $(0,16)$ e França $(0,15)$ foram em 2017 os países que possuem o maior comércio intraindustrial com o Brasil.

Tabela 1 - Índice de comércio intraindústria (IGL) agregado entre o Brasil e a União Europeia (EU), e Brasil e os países da EU, em termos bilaterais-Período de 2006 a 2017

\begin{tabular}{|c|c|c|c|c|c|c|c|c|c|c|c|c|}
\hline BLOCO/PAÍS & 2006 & 2007 & 2008 & 2009 & 2010 & 2011 & 2012 & 2013 & 2014 & 2015 & 2016 & 2017 \\
\hline União Europeia & 0.24 & 0.21 & 0.23 & 0.22 & 0.20 & 0.19 & 0.21 & 0.20 & 0.20 & 0.17 & 0.16 & 0.17 \\
\hline Alemanha & 0.24 & 0.22 & 0.21 & 0.19 & 0.24 & 0.16 & 0.16 & 0.14 & 0.12 & 0.14 & 0.13 & 0.15 \\
\hline Áustria & 0.08 & 0.06 & 0.06 & 0.04 & 0.04 & 0.04 & 0.04 & 0.06 & 0.09 & 0.06 & 0.06 & 0.06 \\
\hline Bélgica & 0.10 & 0.12 & 0.12 & 0.10 & 0.11 & 0.12 & 0.10 & 0.09 & 0.08 & 0.07 & 0.06 & 0.08 \\
\hline Bulgária & 0.00 & 0.00 & 0.00 & 0.01 & 0.01 & 0.00 & 0.00 & 0.00 & 0.01 & 0.01 & 0.01 & 0.01 \\
\hline Chipre & 0.00 & 0.00 & 0.00 & 0.01 & 0.01 & 0.00 & 0.00 & 0.00 & 0.00 & 0.00 & 0.00 & 0.00 \\
\hline Croácia & 0.07 & 0.03 & 0.05 & 0.01 & 0.01 & 0.00 & 0.00 & 0.00 & 0.01 & 0.01 & 0.00 & 0.01 \\
\hline Dinamarca & 0.23 & 0.16 & 0.17 & 0.18 & 0.14 & 0.26 & 0.21 & 0.19 & 0.14 & 0.20 & 0.31 & 0.35 \\
\hline Eslováquia & 0.11 & 0.13 & 0.10 & 0.12 & 0.12 & 0.25 & 0.26 & 0.21 & 0.19 & 0.18 & 0.14 & 0.13 \\
\hline Eslovênia & 0.01 & 0.01 & 0.02 & 0.01 & 0.01 & 0.01 & 0.01 & 0.01 & 0.01 & 0.01 & 0.00 & 0.01 \\
\hline Espanha & 0.12 & 0.10 & 0.10 & 0.09 & 0.10 & 0.10 & 0.09 & 0.08 & 0.08 & 0.09 & 0.13 & 0.10 \\
\hline Estônia & 0.01 & 0.01 & 0.00 & 0.01 & 0.01 & 0.08 & 0.15 & 0.08 & 0.24 & 0.18 & 0.11 & 0.08 \\
\hline Finlândia & 0.04 & 0.03 & 0.03 & 0.02 & 0.02 & 0.04 & 0.04 & 0.03 & 0.03 & 0.03 & 0.03 & 0.04 \\
\hline França & 0.19 & 0.18 & 0.17 & 0.19 & 0.18 & 0.15 & 0.12 & 0.11 & 0.12 & 0.13 & 0.17 & 0.16 \\
\hline Grécia & 0.01 & 0.06 & 0.01 & 0.01 & 0.01 & 0.01 & 0.01 & 0.01 & 0.00 & 0.01 & 0.01 & 0.01 \\
\hline Holanda & 0.14 & 0.13 & 0.10 & 0.07 & 0.08 & 0.08 & 0.06 & 0.05 & 0.05 & 0.04 & 0.04 & 0.05 \\
\hline Hungria & 0.02 & 0.04 & 0.06 & 0.04 & 0.03 & 0.04 & 0.04 & 0.04 & 0.04 & 0.04 & 0.05 & 0.05 \\
\hline Irlanda & 0.16 & 0.15 & 0.13 & 0.12 & 0.10 & 0.09 & 0.09 & 0.09 & 0.08 & 0.10 & 0.10 & 0.09 \\
\hline Itália & 0.00 & 0.00 & 0.00 & 0.01 & 0.00 & 0.00 & 0.00 & 0.00 & 0.00 & 0.00 & 0.01 & 0.01 \\
\hline Letônia & 0.02 & 0.01 & 0.00 & 0.00 & 0.00 & 0.01 & 0.00 & 0.01 & 0.00 & 0.00 & 0.00 & 0.00 \\
\hline Lituânia & 0.10 & 0.11 & 0.09 & 0.06 & 0.03 & 0.03 & 0.03 & 0.03 & 0.02 & 0.03 & 0.03 & 0.02 \\
\hline Luxemburgo & 0.06 & 0.06 & 0.05 & 0.03 & 0.04 & 0.04 & 0.03 & 0.02 & 0.02 & 0.03 & 0.02 & 0.02 \\
\hline Malta & 0.05 & 0.05 & 0.11 & 0.06 & 0.10 & 0.14 & 0.23 & 0.14 & 0.20 & 0.08 & 0.05 & 0.08 \\
\hline Polônia & 0.09 & 0.09 & 0.09 & 0.09 & 0.14 & 0.17 & 0.12 & 0.08 & 0.07 & 0.09 & 0.10 & 0.09 \\
\hline Portugal & 0.03 & 0.03 & 0.03 & 0.03 & 0.03 & 0.03 & 0.02 & 0.03 & 0.03 & 0.03 & 0.05 & 0.03 \\
\hline R. Tcheca & 0.09 & 0.09 & 0.07 & 0.05 & 0.04 & 0.08 & 0.07 & 0.05 & 0.02 & 0.04 & 0.03 & 0.08 \\
\hline Reino Unido & 0.14 & 0.11 & 0.10 & 0.07 & 0.07 & 0.08 & 0.08 & 0.08 & 0.09 & 0.08 & 0.08 & 0.08 \\
\hline Romênia & 0.01 & 0.05 & 0.07 & 0.07 & 0.06 & 0.06 & 0.06 & 0.04 & 0.03 & 0.05 & 0.07 & 0.07 \\
\hline Suécia & 0.17 & 0.19 & 0.17 & 0.13 & 0.12 & 0.11 & 0.12 & 0.10 & 0.11 & 0.10 & 0.09 & 0.11 \\
\hline
\end{tabular}

Fonte: Elaborado própria.

A Dinamarca foi o país que mais se destacou na análise do índice de Grubel e Lloyd, e, apesar de ter apresentado quedas no índice ao longo do período, foi o país que, de 2006 a 2017, apresentou a maior elevação no índice de comércio intraindústria, dessa forma, as trocas comerciais entre o Brasil e a Dinamarca são de produtos da mesma indústria. Conforme dados do MDIC (2018), a Dinamarca tem uma pequena participação no comércio brasileiro (não passou de $0,4 \%$ tanto nas exportações como importações brasileiras em 2017), sendo que essas trocas comerciais ocorreram em indústrias de manufaturados. Em 2017, 77,9\% das 
exportações brasileiras para esse país foram de manufaturas, sendo medicamentos para Medicina Humana, detentor de $47 \%$ dessas exportações. Já em relação às importações, 99,2\% do total importado pelo Brasil, em 2017, são de produtos manufaturados, sendo também produtos de medicamentos para Medicina Humana, com uma participação de $31 \%$. Sendo assim, está ocorrendo comércio do tipo intraindústria entre Brasil e Dinamarca. Silva, Silva e Zilli (2010) abordam que o setor manufatureiro se caracteriza em um comércio intraindustrial, dessa maneira, como as trocas entre esses países ocorreram basicamente em produtos desse setor, isso caracteriza-se como um dos motivos do comércio intraindústria entre o Brasil Dinamarca ser mais expressivo.

Já o Chipre, dentre todos os países analisados, foi o único que apresentou, em quase todos os anos analisados, IGL igual a zero, com exceção apenas dos anos de 2009 e 2010. O Brasil exporta produtos básicos como café cru para esse país, mas o Chipre apresenta uma insignificante participação $(0,001 \%)$ nas importações brasileiras de alguns tipos de produtos manufaturados como pulverizadores.

$\mathrm{Na}$ Tabela 2, são apresentados os resultados do índice de comércio intraindústria entre o Brasil e os países da União Europeia, através da análise setorial. Para isso, os dados foram agrupados conforme a classificação de Thorstensen et. al. (1994), em quatorze setores, utilizando como base o Sistema Harmonizado e a Nomenclatura Comum do Mercosul, como destacado na metodologia.

Observa-se, através dos dados apresentados na Tabela 2, que a maioria dos setores teve redução no comércio intraindustrial de 2006 a 2017, assim como no agregado. Apenas os setores de alimentos e bebidas; calçados e couros; e madeira e mobiliário apresentaram aumento de 2006 para 2017, entretanto, esses mesmos setores são os que possuem os menores índices de comércio intraindústria durante todo o período analisado.

Tabela 2 - Índice de comércio intraindústria (IGL) por setores, entre o Brasil e União Europeia (2006-2017)

\begin{tabular}{|c|c|c|c|c|c|c|c|c|c|c|c|c|c|}
\hline NCM & Setor & 2006 & 2007 & 2008 & 2009 & 2010 & 2011 & 2012 & 2013 & 2014 & 2015 & 2016 & 2017 \\
\hline 1 a 24 & $\begin{array}{l}\text { Alimentos e } \\
\text { Bebidas }\end{array}$ & 0,02 & 0,02 & 0,03 & 0,03 & 0,03 & 0,03 & 0,03 & 0,03 & 0,03 & 0,04 & 0,03 & 0,04 \\
\hline 25 a 27 & Minerais & 0,14 & 0,10 & 0,19 & 0,16 & 0,10 & 0,15 & 0,25 & 0,26 & 0,24 & 0,09 & 0,10 & 0,08 \\
\hline 28 a 38 & $\begin{array}{l}\text { Produtos } \\
\text { Químicos }\end{array}$ & 0,24 & 0,22 & 0,20 & 0,20 & 0,20 & 0,20 & 0,17 & 0,17 & 0,17 & 0,13 & 0,14 & 0,16 \\
\hline
\end{tabular}




\begin{tabular}{|c|c|c|c|c|c|c|c|c|c|c|c|c|c|}
\hline 39 a 40 & $\begin{array}{c}\text { Plásticos e } \\
\text { Borracha }\end{array}$ & 0,43 & 0,40 & 0,43 & 0,46 & 0,41 & 0,40 & 0,37 & 0,33 & 0,34 & 0,35 & 0,35 & 0,35 \\
\hline $\begin{array}{l}41 \text { a } 43 \text { e } \\
64 \text { a } 67\end{array}$ & $\begin{array}{l}\text { Calçados e } \\
\text { Couros }\end{array}$ & 0,07 & 0,06 & 0,05 & 0,04 & 0,03 & 0,05 & 0,06 & 0,06 & 0,07 & 0,08 & 0,09 & 0,08 \\
\hline 44 a 46 & $\begin{array}{l}\text { Madeira e } \\
\text { Mobiliário }\end{array}$ & 0,02 & 0,02 & 0,03 & 0,04 & 0,05 & 0,07 & 0,08 & 0,08 & 0,08 & 0,09 & 0,07 & 0,06 \\
\hline 47 a 49 & $\begin{array}{l}\text { Papel e } \\
\text { Celulose }\end{array}$ & 0,16 & 0,13 & 0,14 & 0,15 & 0,14 & 0,15 & 0,13 & 0,14 & 0,13 & 0,10 & 0,09 & 0,08 \\
\hline 50 a 63 & Têxtil & 0,28 & 0,27 & 0,25 & 0,18 & 0,20 & 0,20 & 0,16 & 0,17 & 0,17 & 0,22 & 0,25 & 0,24 \\
\hline 68 a 72 & $\begin{array}{l}\text { Minerais Não } \\
\text { Metálicos }\end{array}$ & 0,26 & 0,27 & 0,29 & 0,38 & 0,25 & 0,20 & 0,13 & 0,15 & 0,18 & 0,21 & 0,11 & 0,20 \\
\hline 73 a 83 & $\begin{array}{l}\text { Metais } \\
\text { Comuns }\end{array}$ & 0,25 & 0,29 & 0,29 & 0,27 & 0,25 & 0,23 & 0,23 & 0,22 & 0,28 & 0,17 & 0,17 & 0,19 \\
\hline 84 a 85 & $\begin{array}{l}\text { Máquinas e } \\
\text { Equipamentos }\end{array}$ & 0,46 & 0,41 & 0,38 & 0,34 & 0,35 & 0,36 & 0,40 & 0,32 & 0,33 & 0,34 & 0,36 & 0,36 \\
\hline 86 a 89 & $\begin{array}{l}\text { Materiais de } \\
\text { Transporte }\end{array}$ & 0,51 & 0,41 & 0,48 & 0,44 & 0,38 & 0,25 & 0,29 & 0,25 & 0,25 & 0,24 & 0,16 & 0,33 \\
\hline 90 a 92 & $\begin{array}{c}\text { Otica e } \\
\text { Instrumentos }\end{array}$ & 0,23 & 0,20 & 0,18 & 0,17 & 0,15 & 0,14 & 0,13 & 0,11 & 0,14 & 0,14 & 0,16 & 0,16 \\
\hline 93 а 99 & Outros & 0,23 & 0,19 & 0,17 & 0,16 & 0,19 & 0,26 & 0,30 & 0,27 & 0,29 & 0,29 & 0,25 & 0,16 \\
\hline
\end{tabular}

Fonte: Elaboração própria.

O comércio intraindústria Brasil-União Europeia, reportado em todo o período de 2006 a 2017, localiza-se nos setores de materiais de transporte, sendo este grupo de produto o que apresentou os maiores índices de comércio intraindústria de todo o período analisado, que foram nos anos 2006, 2008 e 2009, com valores de 0,51, 0,48 e 0,44 , respectivamente; máquinas e equipamentos, no ano de 2006, com índice de 0,46 - vale destacar que esse setor foi o que apresentou o maior índice de comércio intraindústria dentre todos os setores analisados em 2017, com 0,36 ; e o setor plástico e borracha, com índice de 0,46, em 2009. Desta forma, percebe-se que esses setores são os que possuem o maior comércio intraindústria da Relação Brasil-União Europeia.

Os setores que tiveram os maiores índices de comércio intraindústria são grupos de produtos que apresentam atividades industriais com uma complexidade maior, tanto em tecnologia como em diferenciação dos produtos, que são setores que apresentam características mais propícias de comércio intraindústria. Carmo e Bittencourt (2013) verificaram que os setores que apresentaram os maiores índices de comércio intraindústria entre o Brasil e os países desenvolvidos também foram os de materiais de transporte, máquinas e equipamentos e plástico e borracha. Nos demais setores analisados, o comércio se caracteriza como interindustrial, além disso, 
os resultados evidenciaram que não há tendência de aumento de comércio intraindústria entre o Brasil e o bloco econômico União Europeia.

Atualmente, a China é o mais importante destino das exportações brasileiras, além do Brasil também importar muito deste país. Desde 2009, a China se tornou o maior parceiro comercial do Brasil, e percebe-se, através do índice de comércio intraindustrial agregado, reportado no Gráfico 1, que o comércio entre Brasil e China é totalmente interindustrial.

Gráfico 1- Índice de comércio intraindústria agregado do Brasil e a China - Período de 2006 a 2017

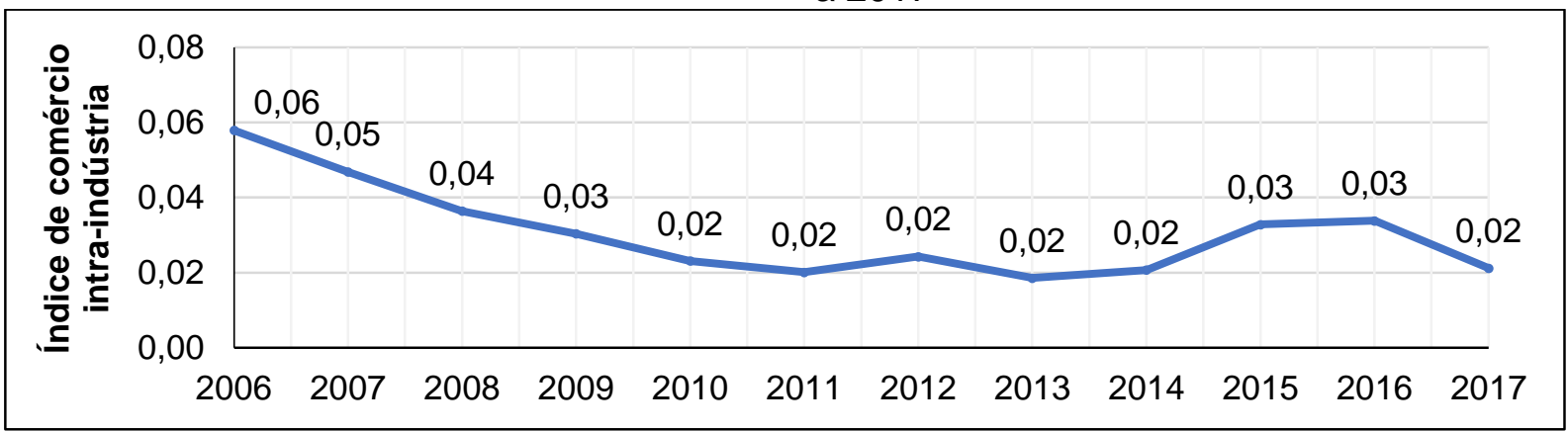

Fonte: Elaboração própria.

O índice de comércio intraindústria variou entre 0,02 a 0,06 durante todo o período analisado, evidenciando que o comércio entre os dois países não apresenta tendência intraindustrial. O maior índice obtido foi em 2006, com 0,06, e, após esse ano, o índice diminuiu. Percebe-se, através do Gráfico 1, que o índice oscilou em torno de 0,02 e 0,03, ou seja, o comércio entre o Brasil e a China ocorre entre indústrias diferentes. O Brasil exporta muitos produtos de baixa intensidade tecnológica e importa de alta tecnologia desse país, e essa diferença justifica o baixo comércio intraindústria agregado entre os dois países, além do que, os produtos exportados do Brasil para a China são compostos por commodities, que se caracterizam por possuir fatores do comércio interindústria.

Os dados reportados na Tabela 3, mostram que os índices de comércio intraindústria por setores entre o Brasil e a China apresentam valores próximos de zero em quase toda a análise ao longo do período de 2006 a 2017, ou seja, não há evidências de que exista um comportamento padrão de comércio intraindústria entre o Brasil e a China, caracterizando, assim, a predominância do comércio interindustrial. Dessa forma, a análise por setores 
corrobora com o resultado obtido de presença de comércio interindustrial entre o Brasil e a China, observado por meio da análise agregada.

Esporadicamente, alguns setores apresentaram certo comércio intraindústria durante o período analisado. É o caso dos setores de materiais de transporte, que apresentou os maiores índices da análise, 0,34, 0,20 e 0,36, nos anos de 2006, 2007 e 2015, respectivamente, e o setor de minerais não metálicos, com índices de 0,34 e 0,17, em 2006 e 2007.

Tabela 3- Índice de comércio intraindústria (IGL) por setores entre o Brasil e a China -

\begin{tabular}{|c|c|c|c|c|c|c|c|c|c|c|c|c|c|}
\hline & \multicolumn{13}{|c|}{ Período de 2006 a 2017} \\
\hline NCM & etor & 006 & 2007 & 2008 & 2009 & 2010 & 2011 & 2012 & 2013 & 2014 & 2015 & 2016 & 2017 \\
\hline I a 24 & & 0,00 & 0,01 & 0,01 & 0,00 & 0,00 & 0,00 & 0,00 & 0,00 & 0,00 & 0,00 & 0,00 & 0,00 \\
\hline 25 a 27 & & 0,00 & 0,00 & 0,00 & 0,00 & 0,00 & 0,00 & 0,00 & 0,00 & 0,00 & 0,00 & 0,00 & 0,00 \\
\hline $28 a$ & & 0,13 & 0,14 & 0,09 & 0,10 & 0,08 & 0,06 & 0,08 & 0,00 & 0,06 & 0,04 & 0,04 & 0,05 \\
\hline 9 a 40 & & 0,11 & 0,14 & 0,10 & 0,06 & 0,06 & 0,07 & 0,05 & 0,00 & 0,04 & 0,05 & 0,06 & 0,07 \\
\hline & & 0,01 & 0,01 & 0,01 & 0,01 & 0,01 & 0,01 & 0,01 & 0,00 & 0,01 & 0,01 & 0,01 & 0,02 \\
\hline 4 a 46 & & 0,03 & 0,04 & 0,06 & 0,04 & 0,04 & 0,04 & 0,06 & 0,00 & 0,07 & 0,05 & 0,05 & 0,07 \\
\hline 7 a 49 & & 04 & 0,04 & 0,03 & 0,05 & 0,11 & 0,12 & 0,10 & 0,00 & 0,09 & 0,11 & 0,07 & 0,04 \\
\hline a 63 & 7 & 0,02 & 0,01 & 0,01 & 0,01 & 0,00 & 0,00 & 0,00 & 0,00 & 0,00 & 0,00 & 0,00 & 0,01 \\
\hline 3 a 7 & $\begin{array}{l}\text { Miner } \\
\text { Metál }\end{array}$ & 0,34 & 0,17 & 0,11 & 0,11 & 0,05 & 0,04 & 0,06 & 0,00 & 0,03 & 0,05 & 0,06 & 0,05 \\
\hline 3 a 83 & Metais Comuns & 0,12 & 0,05 & 0,04 & 0,03 & 0,03 & 0,03 & 0,04 & 0,00 & 0,05 & 0,04 & 0,07 & 0,03 \\
\hline 34 a 85 & & 0,09 & 0,06 & 0,05 & 0,05 & 0,04 & 0,04 & 0,05 & 0,00 & 0,04 & 0,06 & 0,08 & 0,07 \\
\hline 86 a & & 34 & 0,20 & 0,13 & 0,04 & 0,05 & 0,03 & 0,04 & 0,00 & 0,03 & 0,36 & 0,01 & 0,02 \\
\hline$\mu$ & & 0,05 & 0,04 & 0,03 & 0,06 & 0,03 & 0,06 & 0,06 & 0,02 & 0,07 & 0,05 & 0,11 & 0,08 \\
\hline 3 a 99 & Outros & 0,01 & 0,00 & 0,00 & 0,00 & 0,00 & 0,00 & 0,00 & 0,01 & 0,01 & 0,01 & 0,01 & 0,01 \\
\hline
\end{tabular}

Fonte: Elaboração própria

Dessa forma, através dessa análise inicial por meio do IGL, constatou-se que o comércio intraindústria entre o Brasil - União Europeia e Brasil - China é baixo, e notou-se queda do índice agregado no período analisado em ambas as relações. Já em relação ao índice setorial, percebe-se que, em alguns setores que são englobados pelo setor manufatureiro, há indícios de comércio intraindústria, como é o caso do setor de materiais de transporte. 


\section{Análise dos Resultados do Modelo Econométrico}

Antes de analisar os resultados obtidos através do modelo econométrico, por meio do teste de Breusch Pagan, verificou-se que há presença de heterogeneidade não observada nas presentes estimações (coeficiente $\theta_{i j}$ ), dessa forma, as estimações por MQO Pooled podem proporcionar resultados inconsistentes e viesados.

Para verificar qual é o comportamento da heterogeneidade do modelo, foi testado o modelo de efeitos aleatórios contra o de efeitos fixos, através do teste de Mundlack. O resultado mostra que a heterogeneidade é correlacionada com os regressores, pois a hipótese de efeitos aleatórios foi rejeitada, aceitando-se a hipótese alternativa de efeito fixo a 1\%. Em relação aos outros testes, constatou-se a presença de heterocedasticidade e correlação contemporânea. Para a correção desses problemas, foram utilizadas as técnicas de estimadores de Feasible Generalized Least Squares (FGLS) para os efeitos aleatórios e de Panel-Corrected Standard Errors (PCSE) para os efeitos fixos, que são estimadores para correção de problemas de heterocedasticidade e correlação contemporânea (BALTAGI, 2005).

Vale destacar, que o melhor modelo obtido foi o de efeitos fixos, entretanto, para a robustez, são apresentados na Tabela 4, os quatro modelos estimados. De modo geral, percebe-se que os resultados em relação aos sinais estão de acordo com a literatura discutida nas seções anteriores, e independentemente da forma estimada, os sinais obtidos são os mesmos, dessa maneira, mostra a robustez dos modelos apresentados.

Ressalta-se que os resultados obtidos através do modelo de efeitos fixos por PPML foram inferiores aos obtidos através dos efeitos fixos por MQO, e isso se deve principalmente ao fato de não haver considerável número de observações zeradas ou faltantes. Cipolla (2013) obteve a mesma conclusão em sua pesquisa, sendo que apenas alguns coeficientes foram estatisticamente significativos através da técnica de PPML. Outro motivo para a maioria das variáveis do modelo PPML não terem apresentado significância estatística está relacionado ao baixo comércio intraindústria obtido entre Brasil- União Europeia e Brasil - China. Dessa forma, a análise se concentra nos resultados dos efeitos fixos por MQO. 
Apesar do modelo (III) não ser a melhor estimação, uma vez que foram obtidos como melhores modelos os de efeito fixo, é válido mencionar que a distância geográfica afeta negativamente o comércio intraindústria entre o Brasil, a União Europeia e a China, assim, quanto mais longe os parceiros comerciais se encontram, menor será o comércio intraindústria entre eles. A distância geográfica é considerada proxy dos custos de transportes, logo, quanto maior forem os custos incorridos no comércio, menor é o comércio intraindústria. Carmo e Bittencourt (2013) obtiveram que custos de transportes reduzem o comércio intraindústria, e, segundo os autores, o comércio com parceiros muito distantes se torna muito oneroso aos países por possuírem altos custos com o frete e também pela demora dos produtos chegarem ao destino final, o que acaba afetando negativamente, não somente o comércio intraindústria entre os países, mas o comércio internacional como um todo.

Independentemente do modelo analisado, o coeficiente ligado à variável de grau de abertura dos parceiros comerciais apresentou sinal positivo e estatisticamente significativo, além disso, variou entre 0,86 a 1,38, ou seja, afeta consideravelmente 0 comércio intraindústria entre o Brasil, os países da União Europeia e a China. Esse resultado corrobora com a análise da Organização de Cooperação e de Desenvolvimento Econômico (OCDE, 2002), que afirma que países mais abertos ao comércio possuem comércio intraindústria mais intenso com seus parceiros comerciais.

Oliveira (1986) discute que o processo de abertura comercial começou nos países a partir das décadas 60 e 70 do século XX, além disso, a estabilização econômica até as crises do petróleo contribuíram para que o comércio intraindústria da maioria das economias passasse de interindústria a intraindústria, ou seja, passou a haver a presença de economias de escala, competição imperfeita e diferenciação dos produtos exportados pelos países. Em relação ao Brasil, houve a abertura comercial nos anos 90, Silva, Silva e Zilli (2010) destacam que esse fato impulsionou o comércio intraindústria do país. Dessa forma, a abertura das economias é um fator importante para o comércio intraindústria para os países, e especificamente, para esta pesquisa, quanto mais abertos forem a União Europeia e a China, maiores serão as relações intraindustriais com o Brasil. 
Vale destacar, que foi verificado também o efeito do grau de abertura do Brasil, entretanto, por invariabilidade dos dados, esta variável foi retirada do modelo, pois, ao se analisar o grau de abertura do Brasil, percebe-se que, dentre os vinte e oito países que compõem a União Europeia e a China, a abertura econômica brasileira é a menor de todas. Essa pequena abertura comercial do Brasil, provoca baixa intensidade de comércio intraindústria com seus parceiros, sendo que, quanto mais fechado o país for, maior é o comércio interindustrial, ou seja, o país se especializa naquilo que possui maior vantagem comparativa. A variável de abertura comercial é pouco utilizada, mas, como já discutido, é uma variável importante, pois é um fator que contribui para a intensificação do comércio intraindústria, então deve ser considerada nas análises.

Quanto menores forem as diferenças de dotações de fatores nos países parceiros comerciais, maiores são as evidências de comércio das mesmas indústrias. Percebe-se, através dos modelos estimados, que o sinal esperado foi alcançado assim como na pesquisa de Paula e Miranda (2017). Dessa maneira, verifica-se que, quando as diferenças de dotações de fatores aumentam em 1\%, o comércio intraindústria entre o Brasil e os países da EU e China tende a diminuir, aproximadamente, 0,67\% (Modelo II). Entretanto, este resultado não foi robusto, visto que foi somente nos efeitos aleatórios que ele apresentou significância estatística, ou seja, nesse caso a diferença de dotações de fatores é um condicionante que afeta negativamente o comércio intraindústria, conforme o modelo de Hecksher-Ohlin $(\mathrm{H}$ O), visto na seção 2 , os países que são capital-abundante tendem a exportar produtos intensivos em capitais e importar produtos intensivos em trabalho, e o inverso é verdadeiro.

Dessa forma, percebe-se, através do resultado obtido com a variável diferença de fatores $(D I F)$, que a diferença de fatores afeta o comércio intraindústria entre os países, mas como a variável não foi estatisticamente significativa nos modelos bem especificados, não se pode afirmar que ela seja um determinante do Cll entre o BrasilUnião Europeia e Brasil- China.

Tabela 4- Resultados dos modelos Pooled, Efeito Aleatório, Efeito Fixo e PPML

\begin{tabular}{c|c|c|c|c}
\hline \multirow{2}{*}{ Variáveis Explicativas } & I & II & III & IV \\
\cline { 2 - 5 } & Pooled & Efeito Aleatório & Efeito Fixo & Efeito Fixo-PPML $^{+}$ \\
\hline Const & $-1,042$ & $-7,734^{* * *}$ & $-13,619^{* * *}$ & -
\end{tabular}




\begin{tabular}{|c|c|c|c|c|}
\hline \multirow{3}{*}{$\operatorname{Ln}($ Distij) } & $(4.912)$ & $(2,526)$ & $(2,275)$ & \\
\hline & $-1,357^{\star \star \star}$ & $-1,843^{\star * *}$ & - & - \\
\hline & $(0,375)$ & $(0,351)$ & & \\
\hline \multirow[t]{2}{*}{$\operatorname{Ln}\left(G a b_{j t}\right)$} & $1,138^{\star \star \star}$ & $1,271^{\star \star \star}$ & $1,251^{\star \star *}$ & $0,861^{*}$ \\
\hline & $(0,181)$ & $(0,142)$ & $(0124)$ & $(0,446)$ \\
\hline \multirow[t]{2}{*}{$\operatorname{Ln}\left(D I F_{i j t}\right)$} & 0,0004 & $-0,669^{\star * *}$ & $-0,007$ & $-0,019$ \\
\hline & $(0,075)$ & $(0,0147)$ & $(0,034)$ & $(0,206)$ \\
\hline \multirow[t]{2}{*}{$L n\left(P I B \_T_{i j t}\right)$} & $0,494^{* \star *}$ & $0,971^{* \star *}$ & $0,575^{\star \star \star}$ & 1,058 \\
\hline & $(0,188)$ & $(0,174)$ & $(0,087)$ & $(1,591)$ \\
\hline \multirow[t]{2}{*}{$\operatorname{Ln}\left(T C_{i j t)}\right.$} & $-0,560$ & $-0,985^{\star \star *}$ & $-1,096^{\star \star \star}$ & $-1,191^{*}$ \\
\hline & $(0,346)$ & $(0,1775)$ & $(0,249)$ & $(0,768)$ \\
\hline \multirow[t]{2}{*}{$\operatorname{Ln}\left(S I M_{i j t}\right)$} & $0,883^{\star * *}$ & $0,809^{\star \star \star}$ & $0,882^{\star \star \star}$ & 0,241 \\
\hline & $(0,969)$ & $(0,038)$ & $(0,040)$ & $(0,795)$ \\
\hline Efeito de tempo & - & Não & Sim & Sim \\
\hline$N^{\circ}$ de Observações & 348 & 348 & 348 & \\
\hline $\mathrm{R}^{2}$ & 0,471 & - & 0,477 & - \\
\hline Prob $>(F)$ & 0,000 & 0,000 & 0,000 & 0,000 \\
\hline Log likelihood & & & & -46.039867 \\
\hline
\end{tabular}

Em relação ao PIB total, percebe-se que o tamanho econômico dos países afeta positivamente o comércio intraindustrial brasileiro, de acordo com Silva e Bittencourt (2017), quanto maior o tamanho econômico, maiores deverão ser as demandas entre os países, podendo gerar diferenciações de produtos. Dessa forma, o aumento de $1 \%$ do tamanho econômico dos países tem um efeito positivo de $0,58 \%$ sobre o comércio intraindustrial brasileiro com seus parceiros comerciais analisados. Hidalgo (1993) obteve que quanto maior é o tamanho do mercado, maiores são as possibilidades de os países terem um comércio intraindústria.

Paula e Miranda (2017) destacam que a similaridade de renda entre os países contribui para o aumento dos fluxos intraindustriais. Como resultado obteve-se coeficiente com sinal positivo, como esperado, e estatisticamente significativo, em três dos quatro modelos analisados. Dessa forma, quanto maior for o índice de similaridade entre os PIBs dos países, maior tende a ser a importância do comércio intraindústria no comércio total, logo, a tendência é que haja o aumento desse comércio entre os países. Para Helpman e Krugman (1985), quanto mais as nações se tornam parecidas, em tecnologias, recursos, tamanho de mercado, etc., menos 
apresentam vantagens comparativas claras, o que impulsiona o comércio intraindústria.

Em relação à variável de custo de comércio, usado o tempo em dias como proxy, em todas as formas estimadas, o coeficiente teve sinal negativo e foi estatisticamente significativo. Sendo assim, maiores custos de comércio afetam o comércio internacional entre os países, nesse caso, o aumento de 1\% no tempo em dias que os países levam para se adequar aos procedimentos de comércio causa uma redução de $1,10 \%$ no comércio intraindustrial do Brasil com os países da União Europeia e a China.

É preciso deixar claro que os custos de comércio são todos aqueles fatores que oneram o comércio internacional, como custo de transporte, barreiras tarifárias e não tarifárias, custos de informação e comunicação, custos de contrato, custos de moeda, infraestrutura, custos de negócios, assim como, são custos os atrasos portuários, a falta de transparência nas normas, a corrupção, o excesso de burocracia e a desatualização de procedimentos aduaneiros (FRANZEN; SILVA, 2016; SOUZA; BURNQUIST, 2009). A preocupação em reduzir os custos do comércio nos países ocorre desde do final dos anos 90 , com as conferências realizadas pela OMC, e, mais recentemente, em 2017, a OMC ratificou o Acordo de Facilitação do Comércio, pelo qual os países precisam se adequar às normas para reduzir esses custos.

Segundo o Comitê de Facilitação de Comércio (CONFAC, 2018), com a implementação do Acordo de Facilitação do Comércio, as exportações mundiais poderiam crescer aproximadamente 1 trilhão de dólares, sendo que os maiores beneficiados seriam os países em desenvolvimento, pois são os que ainda possuem os maiores custos de comércio.

Na maioria das pesquisas que analisam o comércio intraindústria, a única proxy que analisa o impacto dos custos de comércio é a distância geográfica, dessa forma, é necessário que outras proxies que mensurem os custos de comércio sejam inseridas, para verificar como cada tipo de custo afeta o comércio intraindústria. Os resultados apresentados nos modelos (III) e (IV) mostram que a demora na adequação dos procedimentos de comércio aumenta o tempo de comercialização e ocasiona uma redução no comércio intraindústria entre o Brasil- China e Brasil- União 
Europeia, dessa maneira, é importante considerar nas análises de comércio intraindústrias, os custos de comércio.

\section{Considerações Finais}

Este trabalho analisou o comércio intraindústria entre o Brasil, a União Europeia e a China, com o intuito de responder ao seguinte questionamento: quais são os fatores que podem contribuir para uma relação intraindústria entre Brasil - União Europeia e Brasil - China? Dessa forma, o objetivo foi analisar os determinantes do comércio intraindústria entre o Brasil e os países da União Europeia e a China, no período de 2006 a 2017.

Após mensurado o Índice de Grubel e Lloyd para a União Europeia e para a China, verificou-se que o comércio intraindústria brasileiro com esses parceiros comerciais é muito pequeno e não tem apresentado tendência de crescimento, pelo contrário, diminuiu ao longo do período analisado. Assim sendo, os resultados corroboram com a teoria de que o comércio intraindústria entre relações Norte- Sul são do tipo interindustrial, e, nesse caso, é também interindustrial na relação Sul- Sul.

Quanto aos determinantes do comércio intraindústria, constatou-se que o grau de abertura do parceiro, o tamanho econômico dos países, e a similaridade entre as rendas são fatores que contribuem de forma positiva para o comércio intraindustrial.

Observou-se o grande impacto negativo que os custos de comércio exercem sobre o comércio de mesmas indústrias, dessa maneira, é necessário que políticas comerciais que visam à facilitação do comércio sejam implementadas pelos países, principalmente o Brasil, que ainda possui altos custos de comércio. Menores custos de comercialização entre os países contribuem para que as relações comerciais se intensifiquem, contribuindo para o aumento do comércio intraindústria entre os países. Além disso, a política de integração econômica entre os países também se faz necessária, uma vez que a formação de blocos econômicos contribui para o aumento do comércio intraindústria.

Tratando-se das limitações desta pesquisa, evidencia-se que o câmbio é uma variável muito importante na análise de comércio intraindústria, cuja volatilidade é utilizada na literatura como proxy dessa variável. Entretanto, seu cálculo exige os 
dados das taxas de câmbio de todos os países, e essas taxas não estavam disponíveis para alguns países da União Europeia no período analisado, por isso, optou-se por deixar essa variável de fora da análise.

Por fim, evidencia-se que outras pesquisas podem ser realizadas utilizando desagregações maiores de dados, bem como usando outros índices e metodologias para analisar mais profundamente a relação comercial entre o Brasil, a União Europeia e a China, assim como utilizar outros parceiros comerciais. Além disso, seria conveniente a inserção de outras variáveis de custos de comércio que visem captar de maneira mais profunda o impacto dos custos de comércio sobre o comércio intraindústria entre os países, contribuindo, assim, para a literatura e para a formulações de políticas comerciais.

\section{REFERÊNCIAS}

AMANN, J. C.; STONA, F.; GEWEHR, A. C. Comércio intraindustrial brasileiro com países desenvolvidos e em desenvolvimento: análise do período 1997-2013. Revista de Economia, v. 43, n. 1, ano 40, jan./abr. 2016.

ANDERSON, J. A Theoretical Foundation for the Gravity Equation. American Economic Review, Nashville, v. 69, n. 1, p.106-116, 1979.

ANDERSON, J.; van WINCOOP, E. Trade costs. National Bureau of Economic Research (NBER), Working Papers $N^{\circ}$ 10480, 2004.

ANDERSON, J.; WINCOOP E. Gravity with Gravitas: A Solution to the Border Puzzle. American Economic Review, Nashville, v. 93, n. 1, 2003. Disponível em:< https://www2.bc.edu/james-anderson/BorderEffects.pdf>. Acesso em: set. 2018.

BALASSA, B. Tariff reductions and trade in manufactures among the industrial countries. American Economic Review, v.56, n.2, p. 466-473, 1966.

BALDWIN, R. TAGLIONI, D. Gravity for Dummies and Dummies for Gravity Equations. National Bureau of Economic Research (NBER). Cambridge, Working Papers № 12516 , 2006.

BALTAGI, B. Econometric analysis of panel data. John Wiley \& Sons, New York, [SI] 2008.

BALTAR, C. Comércio exterior inter e intraindustrial:Brasil 2003-2005. Economia e Sociedade, Campinas, v. 17, n. 1, ano 32, p. 107-134, abr. 2008.

BANCO MUNDIAL. World Development Indicators Online (WDI). Disponível em: http://www.worldbank.org/. Acesso em: set. 2018. 
BERGSTRAND, J. H. The Generalized Gravity Equation, Monopolist Competition, and the Factor-Proportions Theory in International Trade. Review of Economics and Statistics. v. 67, n. 3, p. 474-481, 1985. Disponível em:

<http://people.hss.caltech.edu/ camerer/SS280/gravitytrade.pdf>. Acesso em: out. 2018.

BOYRIE, M.; KREININ, M. Intra-Industry Trade Revisited: a note. Open Economies Review. V.23, n.4, p. 741-745, 2012.

CARMO, A. S. S. Comércio Inter e Intra-Indústria, Qualidade, Similaridade e Diversificação da Pauta de Exportação: Ensaios sobre o Comércio Internacional Brasileiro. 138 p. Tese (Doutorado em Desenvolvimento Econômico) - Universidade Federal do Paraná. Curitiba, 2014.

CARMO, A. S. S.; BITTENCOURT, M. V. L. O comércio intraindustrial entre Brasil e os países da OCDE: decomposição e análise de seus determinantes. Análise Econômica, Porto Alegre, ano 31, n.60, p.35-58, set. 2013.

CASTELLANO, E.F. A.; OLIVEIRA, C.A; BITTENCOURT, M.V.L. Análise da qualidade do comércio entre Brasil e os países da OCDE. Encontro de Economia Da Região Sul ANPEC Sul,22, 2019, Maringá, PR.

CEPII. Research and Expertise on The World Economy. Disponível em: www.cepii.fr/CEPII/en/welcome.asp. Acesso em: set. 2018.

CHENG, I.; WALL, H. J. Controlling for Heterogeneity in Gravity Models of Trade and Integration. Federal Reserve Bank of St. Louis Review, St. Louis, v. 87, n. 1, 2004.

CIPOLLA, C. Impactos da logística sobre o fluxo de comércio internacional: uma abordagem no modelo gravitacional para o Brasil e seus principais parceiros comerciais. Dissertação (Mestrado em Economia) - Universidade Federal de São Carlos, 2013.

COMEX STAT. 2018. Dados. Ministério do Desenvolvimento, Indústria e Comércio Exterior. Disponível em: http://comexstat.mdic.gov.br/. Acesso: set. 2018.

CONFAC - COMITÊ NACIONAL DE FACILITAÇÃO DE COMÉRCIO. Relatório de Atividades de 2017 e 2018. 2018. Disponível em:http://www.camex.gov.br/images/PDF/Confac/ltem-9--Relatrio-atividades-Confac-2017-2018-ATUALIZADO.pdf. Acesso em: set. 2018.

FALVEY, R. E.; KIERZKOWSKI, H. Product quality, intra-industry trade and (im)perfect competition. In: Protection and Competition in International Trade, H. Kierzkowski (Ed.). Clarendon Press: Oxford, p. 143-161, 1987.

FEISTEL, P. R.; HIDALGO, Á. B. O Intercâmbio Brasileiro - MERCOSUL: Uma Questão do Aproveitamento das Vantagens Comparativas a Nível Regional. 2011. In: Encontro Nacional de Economia, ANPEC, 37., Foz do Iguaçu. Anais... Foz do Iguacú,2011.

FRANZEN, T.E.; DA SILVA, O.M. Os custos totais do comércio bilateral brasileiro:determinantes e evolução recente. Revista Visión Contable, v. 14, n. 14, 2016. 
GRANÇO, G. Comércio Intra-indutrial Brasileiro: Análise dos determinantes através da Equação Gravitacional. 88 p. Dissertação de mestrado. Universidade de São Paulo Escola Superior de Agricultura Luiz de Queiroz. Piracicaba, 2011.

GREENAWAY, D. \& THARAKAN, P. K. M. Imperfect Competition and International Trade. 1aㅡ. ed. Sussex: Wheatsheaf Books, 1986.

GREENAWAY, D.; MILNER, C. R. Trade theory and the less developed countries. In (Ed.), G., editor, Surveys in Development Economics. Basil Blackwell, Oxford, p. 11- 55, 1989.

GREENE, W. H. Econometric Analysis. 7ํㅡ. Ed. Singapura: Pearson Education, 2012. 1056p.

GRUBEL, H. G.; LLOYD, P. J. Intra-Industry Trade: The Theory and Measurement of International Trade in Differentiated Products. London, MacMillan, 1975.

HELPMAN, E. Imperfect competition and international trade: evidence from fourteen industrialized countries. Journal of the Japanese and International Economies, v. 1,p. 6281, jun. 1987.

HELPMAN, E.; KRUGMAN, P. Market structure and foreign trade. Brighton, UK: Harvester Wheatsheaf, 1985.

HIDALGO, A. B. O intercâmbio comercial brasileiro intra-indústria: uma análise entre indústrias e entre países. Revista Brasileira de Economia, Rio de Janeiro, v. 47, n. 2, p. 243- 264, abr./jun. 1993.

HILDGERT, F. The approach to bilateralism: a change in the structure of World trade. Stockholm: Svenska Handelsbank Index, p. 175-188, 1935.

KRUGMAN, P. R. Increasing returns monopolistic competition and international trade. Journal of International Economics, n. 9, v. 4, nov. 1979.

LANCASTER, Kelvin. Intra-industry trade under perfect monopolistic competition. Journal of International Economics, p. 151-175, 1980.

LEONTIEF, W. Domestic production and foreign trade: the american capital position reexamined. Proceding of the American Philosophical Society, v. 97, p.332-349, 1953.

LINDER, B. An essay on trade and transportation, Wiley, New York, 1961.

LINNEMANN, H. An econometric study of international trade flows. Amsterdam: NorthHolland, 1966.

LOERTSCHER, R. \& WOLTER, F. Determinants of intra-industry trade: among countries and across countries. Weltwirtschaftliches Archiv, v.116, n.2, p. 280-293, 1980.

MAGEE, C. New Measures of Trade Creation and Trade Diversion. Journal of International Economics, v. 75, p. 340-362, 2008. 
MARTINS, M.M.V. O Impacto das Medidas do Acordo de Facilitação de Comércio nos Custos Bilaterais Não Tarifários do Comércio Brasileiro. 2018. 120 p. Dissertação (Magister Scientiae) - Universidade Federal de Viçosa, Viçosa, MG, 2018.

MDIC, 2018, Ministério do Desenvolvimento, Indústria e Comércio Exterior - COMEX VIS. Disponível em :http://www.mdic.gov.br/comercio-exterior/estatisticas-de-comercioexterior/comex-vis/frame-pais. Acesso em: set. 2018.

MESQUITA, P. E. A Organização Mundial do Comércio . Brasília : FUNAG, 2013, 105 p. MISSAGGIA, S. Z.; FEISTEL, P. R. O modelo de gravidade e o efeito fronteira: uma análise do comércio do estado do Rio Grande do Sul com os países do BRICS. XX Encontro Nacional de Economia (ANPEC), Florianópolis - SC, 2015.

MOREIRA, T.; PAULA, N, de. Evolução do comércio intraindustrial entre Brasil e Estados Unidos no período de 1997 a 2008. Revista de Economia, v.36, n.3, ano 34, p.95 -109, set./dez.2010.

OCE - OBSERVÁTORIO DE COMPLEXIDADE ECONÔMICA. Brasil. Disponível em: https://oec.world/en/profile/country/bra/. Acesso em: 17 set. 2019.

OLIVEIRA, M. H. Evidências empíricas do comércio intraindustrial. Revista Brasileira de Economia, v. 40, n.3, p. 211-232, 1986.

ORGANIZAÇÃO PARA A COOPERAÇÃO E DESENVOLVIMENTO ECONÔMICO (OCDE). Intra-industry and intra-firm trade and the internationalisation of production, Economic Outlook, Capítulo V, p. 160-170, 2002.

PAULA, J.S, DE; MIRANDA, M.I.C. Análise do padrão de comércio entre os países do BRICS. Ensaios FEE, Porto Alegre, v. 37, n. 4, p. 1005-1032, mar. 2017.

SANTOS SILVA, J. M. C.; TENREYRO S. The log of gravity. The Review of Economics and Statistics, Cambridge, v. 88, n. 4, 2006.

SARQUIS, J. B. Comércio internacional e crescimento econômico no Brasil. Brasília: Fundação Alexandre de Gusmão, 2011.

SILVA, A. F.; SILVA, O. M.; ZILLI, J. B. Evolução e contribuição do comércio intraindústria para o crescimento do comércio total entre Brasil e Argentina.Revista de Economia, v. 36, n. 2,ano 34, p.7- 24, 2010.

SILVA, C.D.B.; BITTERCOURT, M.V.L. O comércio intraindustrial do Mercosul e a Volatilidade da taxa de câmbio. Anais... XX Encontro de Economia da Região Sul. 2017, Porto Alegre, Rio Grande do Sul. ANPEC-Sul. 2017

SOUZA, M. J. P; BURNQUIST, H. L. Facilitação de comércio e impactos sobre o comércio bilateral. Estudos Econômicos, v. 41, n. 1, p. 91-118, 2011.

THE WORLD BANK. Historical Data Sets and Trends Data. Disponível em: https://www.doingbusiness.org/en/custom-query. Acesso em: set. 2018. 
THORSTENSEN, V. et al. O Brasil frente a um mundo dividido em blocos. São Paulo: Instituto Sul-Norte, 1994.

THORSTENSEN, V. A OMC - Organização Mundial do Comércio e as negociações sobre comércio, meio ambiente e padrões sociais. Revista Brasileira de Política Internacional, v.41, n.2, pp.29-58, 1998.

TINBERGEN, J. Shaping the world economy-suggestions for an international economic policy, The Twentieth Century Fund, 1962.

VASCONCELOS, C. R. F. O Comércio Brasil- Mercosul na Década de 90: Uma análise pala Ótica do Comércio Intra- Indústria. Revista Brasileira de Economia (RBE), 57 (1), p. 283313, Rio de Janeiro, Jan/Mar. 2003.

WOOLDRIDGE, J. M., Introdução à econometria: uma abordagem moderna. São Paulo: Pioneira Thomson Learning, 2006. 708 p.

WTO-WORLD TRADE ORGANIZATION. International Trade Statistics 2007.2018. Disponível em: https://www.wto.org/english/res_e/statis_e/its2007_e/its07_toc_e.htm. Acesso em: 14 set. 2019.

WTO-WORLD TRADE ORGANIZATION. World Trade Statistical Review 2018. 2018. Disponível em: https://www.wto.org/english/res_e/statis_e/wts2018_e/wts2018_e.pdf. Acesso em: 14 set. 2019.

YEATS, A. Does Mercosur's Trade Performance Raise Concerns about the Effects of Regional Trade Arrangements?.Policy Research Working Paper N 1729, 1997. Disponível em:

http://documents.worldbank.org/pt/publication/documentsreports/documentlist?colti=\%20Res earch\%20working\%20paper. Acesso em: 10 out. 2018.

\section{NOTAS DE AUTOR}

\section{CONTRIBUIÇÃO DE AUTORIA}

Angel Maitê Bobato - Concepção e elaboração do manuscrito. Coleta de dados. Tratamento dos dados. Construção dos índices. Estimação dos Modelos. Análise e discussão dos Resultados. Revisão e aprovação da versão final do trabalho.

Daniel Arruda Coronel - Concepção. Participação na escolha da amostra de parceiros comerciais. Participação na discussão dos resultados. Revisão e aprovação da versão final do trabalho.

Paulo Ricardo Feistel - Concepção. Participação na escolha da amostra de parceiros comerciais. Participação da formalização dos índices e do modelo. Participação ativa do referencial teórico e da discussão dos resultados. Revisão e aprovação da versão final do trabalho

\section{FINANCIAMENTO}

O presente trabalho foi realizado com apoio da Coordenação de Aperfeiçoamento de Pessoal de Nível Superior Brasil (CAPES) - Código de Financiamento 001.

\section{CONSENTIMENTO DE USO DE IMAGEM}

Não se aplica. 
BOBATO, CORONEL, FEISTEL

APROVAÇÃO DE COMITÊ DE ÉTICA EM PESQUISA

Não se aplica.

CONFLITO DE INTERESSES

Não se aplica.

\section{LICENÇA DE USO}

Este artigo está licenciado sob a Licença Creative Commons CC-BY. Com essa licença você pode compartilhar, adaptar, criar para qualquer fim, desde que atribua a autoria da obra.

\section{HISTÓRICO}

Recebido em: 29-06-2020

Aprovado em: 21-08-2020 